\title{
The Effect of Quality of Work Life on Worker Performance When Work from Home through Job Satisfaction and Organizational Commitment as Intervening Variables (Case Study at PT Patra Jasa Head Office)
}

\author{
Muhammad Ihsan Hidayat and Eny Ariyanto
}

\section{ABSTRACT}

\begin{abstract}
This study aims to determine the effect of quality of work life on worker performance when working from home (WFH) with job satisfaction and organizational commitment as intervening variables at PT Patra Jasa Head Office. The research method used is a quantitative method. The research population is all employees of PT Patra Jasa with a minimum working period of 1 year, which is 144 people. All members of the population are used as members of the sample (census technique). Primary data collection using a questionnaire instrument. The technique of analyzing and testing the hypothesis is using the Structural Equation Model (SEM) with the SmartPLS version 3.0 application. Partial results of hypothesis testing prove that the quality of work life, organizational commitment, and quality of work life through organizational commitment have no positive and significant effect on worker performance when WFH. Job satisfaction and quality of work life through job satisfaction have a positive and significant effect on worker performance when WFH. Furthermore, simultaneous hypothesis testing with multiple linear regression models has a coefficient of determination (R2) of $67 \%$, quality of work life through job satisfaction and organizational commitment has a strong effect on worker performance when WFH.
\end{abstract}

Keywords: Job Satisfaction, Organizational Commitment, Quality of Work Life, Worker Performance when Work from Home.

\author{
Submitted : October 31, 2021 \\ Published : November 23, 2021 \\ ISSN: 2507-1076 \\ DOI: $10.24018 / \mathrm{ejbmr} .2021 .6 .6 .1154$ \\ Muhammad Ihsan Hidayat \\ Master of Management, Faculty of \\ Economics and Business, Mercu Buana \\ University, Jakarta, Indonesia. \\ (e-mail: \\ muhammadihsanhidayat ${ }^{@}$ gmail.com) \\ Eny Ariyanto* \\ Faculty of Economics and Business, \\ Mercu Buana University, Jakarta, \\ Indonesia. \\ (e-mail: eny_ariyanto@yahoo.com)
}

*Corresponding Author

\section{INTRODUCTION}

Performance is the result of work that has a strong relationship with organizational strategic objectives, customer satisfaction and contributes to the economy (Bernardin \& Russel, 1993). Sometimes workers encounter situations that can affect the quality of their performance, one of which is the current Covid-19 pandemic situation. Currently, the company, according to government regulations, applies a system of limiting the number of workers in the workplace by implementing the Work from Office (WFO) and Work from Home (WFH) work systems in turns. with the WFH system, this condition can affect the performance produced by workers.

Some of them carry out dual roles as workers and take care of the household. There are also those whose home environment is not conducive to being used as a place to work. They are required to still be able to produce good performance even in conditions of various factors that can interfere with their time and work conduciveness. To achieve its goals, all companies will certainly do their best, including at the head office of PT Patra Jasa.

The author conducted a pre-survey to find out if there were problems in the performance of workers when WFH. This survey was conducted by sampling 30 workers. From the presurvey observations on the performance of workers during WFH, there are 3 performance indicators in the low category and 4 performance indicators in the medium category. With these results, it can be concluded that the performance of workers when WFH still needs to be improved. The next questionnaire is to find out what variables affect the performance of workers when WFH. The results show that the 3 variables with the highest percentage are quality of work life, organizational commitment, and job satisfaction. From the results of the pre-survey, researchers took the three highest variables that were considered to affect the variable of worker performance when WFH.

The quality of work life is one of the main issues that need to get the attention of the organization. The quality of work life is a comprehensive construct that includes an individual's job-related well-being and the extent to which work experience is rewarding and satisfying (Zin, 2004). Previous research has shown that the quality of work life has a positive and significant impact on organizational performance (Rathamani \& Ramchandra, 2013). With the quality of work 
life also raises the expectations of workers to remain in the organization. Quality of work life gives hope to workers' satisfaction about the needs of members through enriching experience in the organization.

Satisfaction is viewed as a positive statement of workers' assessment of what the organization has done for its workers. Job satisfaction is an affective reaction that is emotional towards one's work which is obtained from the comparison of the actual results of the incumbent with the desired results (needed, appropriate, and so on) (Weiss et al., 1967). The results of the study prove that there is a positive relationship between job satisfaction and employee performance (Hira \& Waqas, 2012).

In addition, organizational commitment is claimed to be another factor that affects worker performance. Organizational commitment is a force that binds an individual to an action that is relevant to one or more targets (Allen \& Meyer, 1990). In the study, it was proven that organizational commitment had a significant positive effect on worker performance (Folorunso et al., 2014).

Organizations seek to benefit from employee commitment such as improving quality or productivity, so organizations must bridge and have a commitment to creating a work environment that pays more attention to the needs and satisfaction of workers (Ramadan, 2015). Researchers conducted interviews with 5 workers at the PT Patra Jasa Head Office with supervisory levels and above related to the relationship between quality of work life, organizational commitment, and job satisfaction on worker performance when WFH. They argue that the quality of work life can also have an influence on performance through the formation of job satisfaction and organizational commitment. When their work life is of high quality, employees will feel satisfied and will form a commitment to their organization that will influence them to give their best performance when WFH. Therefore, job satisfaction and organizational commitment are used as intervening variables in this study.

Departing from these problems, this research is limited by exogenous variables, namely the quality of work life which consists of seven dimensions, namely growth and development, participation, work environment, supervision, salary and benefits, social relations, and work integration (Zin, 2004). Then the endogenous variable is performance which consists of six dimensions, namely quality, quantity, timeliness, cost effectiveness, interpersonal relationships, and the need for supervision (Bernardin \& Russel, 1993). Furthermore, the intervening variable is job satisfaction by using the dimensions of intrinsic and extrinsic satisfaction (Weiss et al., 1967). The next intervening variable is organizational commitment with dimensions of affective, normative, and continuance commitment (Allen \& Meyer. 1990).

\section{LITERATURE REVIEW}

\section{A. The Effect of Quality of Work Life on Worker Performance When WFH}

Performance is influenced by several variables, one of which is the quality of work life. The quality of working life has an influence on the productivity of textile industry workers in Perundurai (Rathamani \& Ramchandra, 2013). Similar results also show that there is a positive relationship between quality of work life and performance (Majumdar et al., 2012), (Shahbazi et al., 2011). Thus, the following hypothesis can be drawn:

Hypothesis H1: There is a positive and significant influence on the quality of work life on the performance of workers when WFH.

\section{B. The Effect of Quality of Work Life on Job Satisfaction}

There is a significant and positive correlation between quality of work life and job satisfaction of members of the Faculty of Medical Sciences, Zahedan University (Kermansaravi et al., 2015). The results of other studies show that there is a positive influence between the dimensions of quality of work life on job satisfaction in workers (Fatehi et al., 2015). Furthermore, there are studies that prove that in general there is a significant relationship between the quality of work life and job satisfaction (Othman \& Lieng, 2009). Referring to the evidence of research findings, the following hypotheses can be formulated:

Hypothesis H2: There is a positive and significant influence on the quality of work life on job satisfaction.

\section{The Effect of Quality of Work Life on Organizational Commitment}

In a study entitled "Study of Relationship Quality of Work life and Organizational Commitment" resulted in a conclusion that the two variables are closely related to each other. The quality of work life has a significant effect on the commitment of employees in the company (Farjad, 2013). In a study that aims to investigate the relationship between quality of work life and organizational commitment among a sample of workers in Malaysia. The results of this study indicate that there is a relationship between quality of work life and organizational commitment (Normala, 2010). Then there is research that proves that there is a positive and significant relationship between the quality of work life and organizational commitment (Sajjad \& Abbasi, 2014). As for the empirical facts, it can be formulated hypothesis statements such as:

Hypothesis H3: There is a positive and significant influence on the quality of work life on organizational commitment.

\section{The Effect of Job Satisfaction on Worker Performance When WFH}

There is a positive relationship between job satisfaction on worker performance (Hira \& Waqas, 2012). There are studies showing that aspects of job satisfaction such as salary, promotion, job safety, security, working conditions, job autonomy, relationships with colleagues, relationships with superiors, and the nature of work significantly affect the level of job satisfaction and worker performance (Khan et al., 2011). Likewise, other studies have shown that there is a positive and significant relationship between job satisfaction factors and worker performance (Fadlallh, 2015). Thus, the following hypothesis can be drawn:

Hypothesis H4: There is a positive and significant effect of job satisfaction on worker performance when WFH. 


\section{E. The Effect of Organizational Commitment on Worker Performance When WFH}

A study shows that the dimensions of organizational commitment jointly and independently affect employee performance among academic staff (Folorunso et al., 2014). Another study states that there is a significant relationship between organizational commitment to employee performance (Rafiei et al., 2014). Furthermore, there is research showing that the three dimensions of organizational commitment have a positive and significant correlation on employee performance (Memari et al., 2013). Referring to the evidence of research findings, the following hypotheses can be formulated:

Hypothesis H5: There is a positive and significant effect of organizational commitment on worker performance when WFH.

F. The Effect of Quality of Work Life on Worker Performance When WFH Through Job Satisfaction and Organizational Commitment

There is an indirect effect between the quality of work life on the performance of workers through organizational commitment and job satisfaction as an intermediate variable (Ramadan, 2015). Furthermore, a study showed that organizational commitment mediates the relationship between quality of work life and performance (Augustine et al., 2016). Then another study showed that the variable quality of work life has a positive effect on job satisfaction; the variable quality of work life has a positive effect on worker performance; job satisfaction variable has a positive effect on worker performance; and the variable quality of work life has an indirect effect through job satisfaction on worker performance (Setiyadi \& Wartini, 2016). As for the empirical facts, it can be formulated hypothesis statements such as:

Hypothesis H6: There is a positive and significant influence on the quality of work life on the performance of workers when WFH through job satisfaction.

Hypothesis H7: There is a positive and significant influence on the quality of work life on the performance of workers when WFH through organizational commitment.

Based on the relationship between the variables described above, the conceptual framework and hypotheses can be formulated as follows:

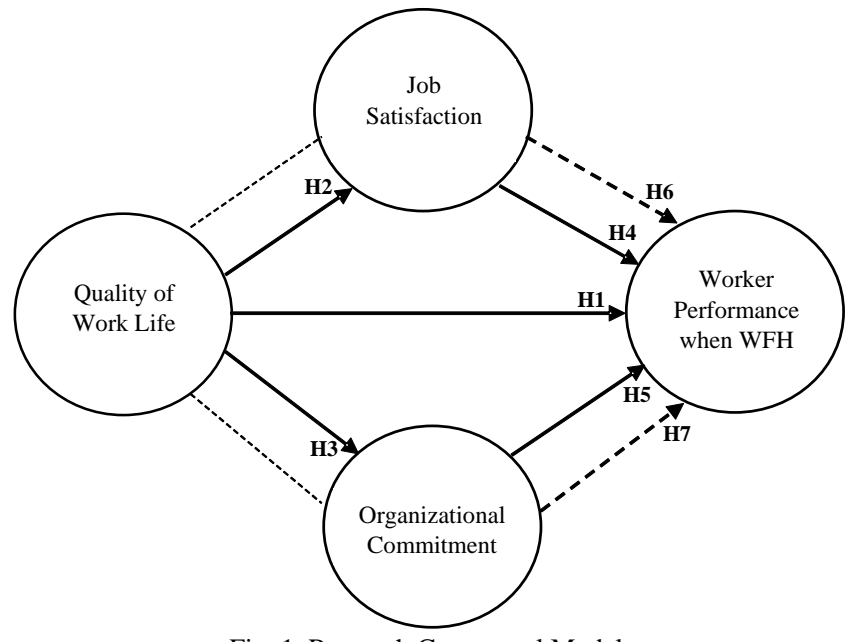

Fig. 1. Research Conceptual Model.

\section{RESEARCH METHOD}

This research was conducted on workers at the head office of PT Patra Jasa with a working period of more than 1 year totaling 144 workers. The sampling technique uses the census technique, so the sample is the same as the population. The data analysis method used in this study is the SEM method with the SmartPLS version 3.0 tool, including:

\section{A. Test Outer Model}

\section{1) Validity test}

Outer loading 0.7 and AVE 0.5. The model has sufficient discriminant validity if the $\sqrt{A V E}$ for each construct $>$ the correlation between the constructs and other constructs in the model (Jogiyanto, 2011).

2) Reliability Test

Composite reliability value > 0.7 (Ghozali \& Latan, 2015).

\section{B. Inner Model Test}

The stronger the path coefficient number is closer to 1 , meaning that the influence of the independent variable is the stronger it affects the dependent variable (Ghozali \& Latan, 2015). Values of $0.67,0.33$, and 0.19 indicate a strong, moderate, and weak model (Jogiyanto, 2011). The value of predictive relevance $(\mathrm{Q} 2)$ is said to be good if $>0$. The goodness of fit model using the SRMR criteria meets the cut off value 0.10 .

\section{Hypothesis Testing}

$T$-statistics $>1.96$ this value is used at the $5 \%$ alpha level and $80 \%$ power (Jogiyanto, 2011).

\section{RESUlTS}

Respondents who participated in this study were broken down by age, gender, last education, and years of service, as follows:

\section{A. Characteristics of Respondents Based on Gender}

Respondents are dominated by women. In a feminineoriented culture, women at work have the role of teaching, caring, and helping others (Gibson et al., 2012). Based on this theory, the work culture in the company is a culture of helping and serving. This is in accordance with the company's business in the field of services and services.

\section{B. Characteristics of Respondents Based on Age}

Respondents are predominantly aged $31-40$ years. Age in the workforce is becoming an increasingly important issue in the next decade, stereotypes of younger workers are considered to be more flexible, productive and have potential (Robbins \& Judge, 2017). This is one of the strengths of HR in the company.

\section{Characteristics of Respondents Based on Education} Level

Respondents are dominated by bachelor education level who are highly educated people, so they have good knowledge and competence.

\section{Characteristics of Respondents Based on Working Period}

Respondents are dominated by 1-5 years of service. 
Working period has a positive relationship with work productivity, this can be seen from the experience and mastery of positions held by old workers better than new workers (Robbins \& Judge, 2017). This shows that the working period of the majority of workers is one of the causes of performance productivity constraints.

Furthermore, descriptive analysis to determine respondents' perceptions, among others:

\section{E. Results of Analysis of Quality of Work Life Variables}

The quality of work life has an average rating of moderate criteria, which is 3.29 . The assessment with low criteria is 1 indicator, medium 10, and high 10. The lowest assessment is an indicator that the salary received has been able to prosper in daily life. Overall, the quality of work life applied by the organization has been going quite well. However, workers still feel that the salary they receive is not enough to improve their daily lives.

\section{F. Results of Job Satisfaction Variable Analysis}

Job satisfaction has an average rating of moderate criteria, which is 3.11. The assessment with medium criteria is 16 indicators and high 4 . The lowest assessment is an indicator of satisfaction with the comparison of the salary received and the work done. Overall, workers are quite satisfied with their work. However, workers still feel not quite satisfied with the comparison of the salary received and the work done.

\section{G. Results of Analysis of Organizational Commitment Variables}

Organizational commitment has an average rating of moderate criteria, which is 3.10 . Ratings with low criteria are 1 indicator, medium 10, and high 1 . The lowest rating is an indicator that is sure not to leave this company even though there is a more profitable offer. Overall, workers are quite committed to the organization. However, workers are still not convinced that they will not leave the company despite a more lucrative offer.

\section{H. Results of Worker Performance Variable Analysis When WFH}

The performance of workers when WFH has an average rating of high criteria is 3.48 . The assessment with medium criteria consists of 5 indicators and a high of 13 . The lowest rating is on the indicator of being able to work with a small error rate when WFH. Overall workers have high performance when WFH. However, workers still feel that they are not sufficiently able to work with a small error rate when WFH.

Furthermore, the outer model test is generated as follows:

\section{Validity Test}

\section{1) Convergent Validity}

All loading factor values $>0.7$ with the lowest value 0.718 and the highest value 0.911 so it is said to be valid. Then all AVE values $>0.5$ so that it can be said to be valid.

TABLE I: AVE

\begin{tabular}{cc}
\hline \hline Variable & AVE \\
\hline Quality of Work Life & 0.640 \\
Job satisfaction & 0.605 \\
Organizational Commitment & 0.671 \\
Worker Performance when WFH & 0.706 \\
\hline \hline Source: Primary data processed (2021).
\end{tabular}

\section{2) Discriminant Validity}

The correlation between the same constructs has the highest value compared to the correlation with other constructs so that this model can be said to be valid.

\section{J. Reliability Test}

Cronbach's alpha and composite reliability values $>0.7$ so it can be said to be reliable.

TABLE II: RELIABILITY TEST

\begin{tabular}{ccc}
\hline \hline Variable & Cronbach's Alpha & Composite Reliability \\
\hline Quality of Work Life & 0.972 & 0.974 \\
Job satisfaction & 0.965 & 0.968 \\
Organizational Commitment & 0.955 & 0.961 \\
Worker Performance when & 0.975 & 0.977 \\
WFH & &
\end{tabular}

Source: Primary data processed (2021).

Furthermore, the analysis of the inner model is evaluated with R2 for the dependent construct. It can be stated that the variable of job satisfaction is strongly influenced by the variable of quality of work life, while the variable of organizational commitment is moderately influenced by the variable of quality of work life, and the variable of worker performance when WFH is strongly influenced by the variables of quality of work life, job satisfaction, and organizational commitment.

\begin{tabular}{cc}
\multicolumn{2}{c}{ TABLE III: VALUE OF R SQUARE } \\
\hline \hline Variable & R Square \\
\hline $\begin{array}{c}\text { Job satisfaction } \\
\text { Organizational } \\
\text { Commitment }\end{array}$ & 0.814 \\
Worker Performance when \\
WFH
\end{tabular}

Then the predictive relevance test $(\mathrm{Q} 2)$ is carried out, the value of Q2 > 0 means the model is said to be good.

TABLE IV: PRedictive ReleVANCE VALUe (Q2)

\begin{tabular}{lcccc}
\hline \multicolumn{1}{c}{ Variable } & SSO & SSE & $\mathrm{Q}^{2}$ \\
\hline Quality of Work Life & $3,024,000$ & $3,024,000$ & \\
Job satisfaction & $2,880,000$ & $1,478,340$ & 0.487 \\
Organizational Commitment & $1,728,000$ & $1,037,715$ & 0.399 \\
Worker Performance when & 2.592 .000 & $1,389,591$ & 0.464 \\
WFH & & & \\
\hline \hline
\end{tabular}

Source: Primary data processed (2021)

Finally, the goodness of fit model with Standardized Root Mean Square Residual (SRMR) meets the cut off value 0.10, so it can be concluded that the model is good.

\begin{tabular}{ccc}
\multicolumn{3}{c}{ TABLE V: GoODNESS OF FIT (GoF) VALUE } \\
\hline \hline Criteria & Saturated Model & Estimated Model \\
\hline SRMR & 0.096 & 0.098 \\
\hline \multicolumn{2}{c}{ Source: Primary data processed (2021) }
\end{tabular}

The following is the analysis of hypothesis testing:

\section{Hypothesis $\mathrm{H} 1$}

The coefficient value of is positive, the t-statistic is 1.063 , and the p-value is 0.288. Conclusion: Hypothesis 1 is rejected, and it is stated that there is no positive and significant effect on the quality of work life on the 
performance of workers when WFH.

\section{Hypothesis $\mathrm{H} 2$}

The coefficient value of is positive, the t-statistic is 71.911, and the p-value is 0.000 . Conclusion: Hypothesis 2 is accepted and stated that there is a positive and significant influence on the quality of work life on job satisfaction.

\section{Hypothesis $\mathrm{H3}$}

The value of the coefficient is positive, the t-statistic is 24,197 , and the p-value is 0.000 . Conclusion: Hypothesis 3 is accepted and stated that there is a positive and significant influence on the quality of work life on organizational commitment.

\section{Hypothesis $\mathrm{H4}$}

The coefficient value of is positive, the t-statistic is 5.089, and the p-value is 0.000 . Conclusion: Hypothesis 4 is accepted and stated that there is a positive and significant effect of job satisfaction on worker performance when WFH.

\section{Hypothesis $\mathrm{H5}$}

The coefficient value of is positive, the t-statistic is 1.148 , and the p-value is 0.252. Conclusion: Hypothesis 5 is rejected, and it is stated that there is no positive and significant effect of organizational commitment on worker performance when WFH.

\section{Hypothesis $\mathrm{H6}$}

The coefficient value of is positive, the t-statistic is 5.013, and the p-value is 0.000. Conclusion: Hypothesis 6 is accepted and stated that there is a positive and significant effect on the quality of work life on worker performance when WFH through job satisfaction.

\section{Hypothesis $\mathrm{H7}$}

The coefficient value of is positive, the t-statistic is 1.167 , and the p-value is 0.244. Conclusion: Hypothesis 7 is rejected, and it is stated that there is no positive and significant effect on the quality of work life on worker performance when WFH through organizational commitment.

Indirect effect testing is done with the Sobel Test. If the pvalue $<0.05$ then there is an indirect effect.

TABLE VI: SOBEL TEST HYPOTHESIS 6

\begin{tabular}{ccccc}
\hline \hline & Input & & Test statistics & p-value \\
\hline ta & 71,911 & Sobel test & 1.147 & 0.252 \\
tb & 5.089 & Aroian test & 1.146 & 0.252 \\
& & Goodman test & 1.148 & 0.251 \\
\hline \hline
\end{tabular}

Source: Primary data processed (2021).

The indirect effect between quality of work life and worker performance when WFH through job satisfaction was significant (full mediation).

TABLE VII: SOBEL TEST HYPOTHESIS 7

\begin{tabular}{ccccc}
\hline \hline & Input & & Test statistics & p-value \\
\hline ta & 24,179 & Sobel test & 1.147 & 0.252 \\
tb & 1.148 & Aroian test & 1.146 & 0.252 \\
& & Goodman test & 1.148 & 0.251 \\
\hline \hline
\end{tabular}

Source: Primary data processed (2021).

The indirect effect between the quality of work life and the performance of workers when WFH through organizational commitment was not significant (no mediation).

\section{DISCUSSION}

\section{A. The Effect of Quality of Work Life on Job Satisfaction}

Job satisfaction is strongly influenced by the quality of work life. This model has one hypothesis, namely hypothesis 2 which is accepted. The average job satisfaction assessment still has moderate criteria, so it needs to be improved. The indicator of the quality of work life that has the greatest correlation to the job satisfaction indicator is that the company supports the company to be able to occupy a higher position in the future. Correlates on indicators of opportunity to get advancement/promotion in work. The majority of workers have a young age, for young workers, not only expect a proud job and a suitable salary but also want the fulfillment of career aspects (Alwi, 2008). Therefore, the company's support for workers to be able to occupy higher positions in the future, needs to be maintained so that job satisfaction can be well maintained.

The indicator of the quality of work life that has the least correlation to the job satisfaction indicator is that the company helps to increase knowledge and ability to do work when WFH. Correlates on indicators of feeling comfortable with the work atmosphere when WFH. The majority of workers have a recent tenure. For workers who do not have a lot of work experience, they need to increase their knowledge and abilities (Bangun, 2012). Therefore, company assistance to increase knowledge and ability to do work when WFH needs to be increased so that the job satisfaction of workers can be further increased.

\section{B. The Effect of Quality of Work Life on Organizational Commitment}

Organizational commitment is moderately affected by the quality of work life. This model has one hypothesis, namely hypothesis 3 which is accepted. The average organizational commitment assessment still has moderate criteria, so it needs to be improved. The indicator of the quality of work life that has the greatest correlation to the indicator of organizational commitment is that the company cares about the community. The correlated indicators of feeling happy can spend the rest of their career in this company. Workers are dominated by women, in a feminine-oriented culture, women at work have the role of teaching, caring, and helping others (Gibson et al., 2012). Therefore, the culture of working in the company is a culture of helping and caring. The company's concern for the community needs to be maintained so that the organizational commitment of the workers can be maintained properly.

The indicator of the quality of work life that has the least correlation with the indicator of organizational commitment is balancing time for work and family when WFH. The correlation indicator of confidence persists in this company in all its conditions. The majority of workers are women, they experience excessive workload related to their dual role as wife/housewife (Gibson et al., 2012). Therefore, providing opportunities for workers to balance time between work and family when WFH needs to be increased so that the organizational commitment of workers can be further increased. 
C. The Effect of Quality of Work Life on Worker Performance When WFH Through Job Satisfaction and Organizational Commitment

Worker performance when WFH is strongly influenced by quality of work life through job satisfaction and organizational commitment. This model has five hypotheses, namely hypotheses $1,4,5,6$, and 7 . Hypotheses 4 and 6 are accepted, while the rest are rejected. Hypothesis 1 was rejected, then the researcher conducted interviews with 5 workers with supervisory level and above regarding their opinions on why the hypothesis was rejected. According to them, because the majority of workers are young. Usually have new roles, such as husband/wife, parents, and also selfdevelopment. Prioritizing work and family balance, so that they not only see work as financial fulfillment but can also provide satisfaction.

Hypothesis 5 was rejected, then the researcher conducted another interview. According to them, the majority of workers are young and have a bachelor's degree. The phenomenon of "jumping lice" is usually found in young workers, fresh graduates, and tend to be educated. There are times when the work they do does not create organizational commitment and, in the end, does not work optimally. Finally, Hypothesis 7 was rejected, then the researcher again conducted interviews. According to them, young workers sometimes find their work boring. Meanwhile, the desire to balance life between work and social life is also a reason for someone to change jobs. Therefore, in addition to the role of quality of work life and organizational commitment, it is also necessary to play a role in job satisfaction that can make its performance optimal.

The results of the analysis of the frequency of respondents' answers on the performance of workers when WFH as a whole already have an average rating of high criteria but there are still 5 indicators of moderate criteria assessment. Based on this, the company still needs to further improve the performance of workers when WFH. The indicators of the quality of work life that have the greatest correlation to the performance indicators of workers when WFH are coworkers who support each other when WFH. Correlate on indicators of ability to cooperate between workers when WFH. Workers are dominated by women, in a feminineoriented culture, women at work have the role of teaching, caring, and helping others (Gibson et al., 2012). Based on this theory, the culture of working in the company is more of a culture of helping and caring. Thus, a culture of mutual support for co-workers when WFH needs to be maintained so that the performance of workers when WFH can be maintained properly.

The indicator of the quality of work life that has the least correlation with the performance indicators of workers when WFH is a safe and healthy work environment when WFH. The correlated indicators can reduce errors when working when WFH. The work is usually carried out in an environment that results in additional loads. Factors causing the increased burden include the physical, mental, and psychological environment. The majority of workers are women. Female workers who have multiple role conflicts certainly affect mental and psychological factors. An unsafe and unhealthy work environment will increase the workload (Kaswan, 2012). Based on the data above, a safe and healthy work environment when WFH needs to be improved so that the performance of workers when WFH can increase.

The job satisfaction indicator that has the greatest correlation to the performance indicators of workers when WFH is the opportunity to complete different jobs when WFH. Correlate on indicators of ability to cooperate between workers when WFH. The majority of young workers expect varied work to avoid boredom. Boredom experienced by young workers is a condition that arises from a combination of work factors and internal factors. This condition causes a person to not function properly (Mangkunegara, 2011). Based on the data above, the opportunities given to workers to complete different jobs when WFH need to be maintained so that the performance of workers when WFH can be maintained properly. The indicator of job satisfaction that has the least correlation to the performance indicators of workers when WFH is having job certainty in the positions given by the company. The correlated indicator is being able to start work on time when WFH. The majority of workers are young. There are several developments that will be completed by young workers, including being responsible for definite tasks (Rivai, 2004). Based on the data above, the provision of job security in positions given by the company needs to be improved so that the performance of workers when WFH can increase.

The indicator of organizational commitment that has the greatest correlation to the performance indicators of workers when WFH is this company has a great meaning for workers. Correlate on indicators of ability to maintain performance when WFH. Between the ages of 20-40 years, workers will focus on career stabilization. Career choice is a long process that involves psychological, sociological, economic, and cultural aspects that can influence the selection that builds a career path (Alwi, 2008). Based on the data above, a great sense of meaning in the company needs to be maintained with psychological, sociological, economic, and cultural aspects that will affect their good perception of the company where they work so that the performance of workers when WFH can be maintained properly.

The indicator of organizational commitment that has the least correlation with the performance indicators of workers when WFH is the belief that they will remain in this company in all conditions. Low correlated indicators are able to work with a small error rate when WFH. Workers are dominated by workers with a bachelor's degree and young age. Most employees are 26-40 years old and educated, they expect their career path to go according to plan and can get success (Bangun, 2012). Based on the data above, confidence remains in this company in all its conditions, it needs to be improved so that the performance of workers when WFH can improve.

\section{CONCLUSION}

Based on the results of research that has been carried out at the PT Patra Jasa Head Office, several conclusions can be drawn as follows:

1. Job satisfaction is strongly influenced by the quality of work life. There is a positive and significant influence on the quality of work life on job satisfaction.

2. Organizational commitment is moderately influenced by the quality of work life. There is a positive and significant 
influence on the quality of work life on organizational commitment.

3. Worker performance when WFH is strongly influenced by quality of work life through job satisfaction and organizational commitment. There is a positive and significant effect on the quality of work life on the performance of workers when WFH.

4. There is a positive and significant effect of job satisfaction on worker performance when WFH.

5. There is no positive and significant effect of organizational commitment on worker performance when WFH.

6. There is a positive and significant influence on the quality of work life on the performance of workers when WFH through job satisfaction.

7. There is a positive and significant influence on the quality of work life on the performance of workers when WFH through organizational commitment.

\section{SUGGESTION}

Suggestions to improve the performance of PT Patra Jasa

Head Office workers when WFH, namely:

1. To increase job satisfaction, it can be done by improving the quality of work life, especially company assistance to workers to increase their knowledge and ability to do work when WFH. Knowledge sharing is needed to increase skills about creativity, persuasion, collaboration, adaptability, and emotional intelligence when WFH.

2. Increasing organizational commitment can be done by improving the quality of work life, especially providing opportunities for workers to balance time between work and family when WFH. The alternative policy is to provide work or assignments only during working hours so that workers can rest and interact with their families when not during working hours.

3. To improve the performance of workers when WFH can be done by improving the quality of work life, job satisfaction, and organizational commitment. The quality of work life that needs to be improved, especially a safe and healthy work environment when WFH. A Sharing Session is needed on how to create a safe and healthy home environment when WFH. Job satisfaction needs to be improved, especially the opportunities given to workers to get advancement/promotion in work. Mentors and sponsors are needed for workers to prepare for promotions and directed career paths. Finally, the organizational commitment that needs to be improved, especially the confidence of workers to stay in this company in all conditions.

4. This research is limited to being carried out in one organization so that it may not necessarily be applied to other organizations. It is hoped that further research will be carried out across organizations so as to get a comprehensive picture of the performance of workers when WFH. This research is also not good enough to be an induction in similar industries because it is limited to research at the head office which is not directly involved in front-line business operations. It is hoped that further research will be carried out with a scope down to front-line operations so that it can be used as an induction in an industry.

\section{REFERENCES}

Allen, N.J., \& J.P., Meyer. (1990). The measurement and antecedents of affective, continuance and normative commitment to the organization. Journal of Occupational Psychology, 63, 1-18.

Alwi, S. (2002), Human resource management competitive advantage strategies. 2nd ed. Yogyakarta: BPFE Yogyakarta.

Augustine, A., Muhammed, M. A., Agyapong, K. (2016). Perceived quality of work life and work performance among university academic staff. International Journal of Current Research and Academic Review, 4, 113.

Bangun, W. (2012), Human resource management, Jakarta: Erlangga Publisher.

Bernardin, J. H. \& Russel J. E. A. (1993). Human resource management: an experiential approach, International Ed. Singapore: The McGraw-Hill Companies, inc.

Fadlallh, A. W. (2015). Impact of job satisfaction on employees performance an aplication on faculty of science and humanity studies University of Salman bin Abdul Aziz Al Aflaj. Internationa Journal of Innovation and research in Educational Sciences., 2(1), 26-32.

Farjad, H R. (2013). Study of relationship of quality of work life (QWL) and organizational commitment. Interdisciplinary Journal of Contemporary Research in Business, 4(9), 449-456.

Fatehi, B., Amini, I., Karimi, A., \& Azizi, B. (2015). Impact of quality of work life on job (Case Study: Sport Teachers in Department of Education from Urmia). Research Journal of Sport Sciences, 3(1), 1522.

Folorunso, O.O., Adewale, A. J., \& Abodunde, S.M. (2014). Exploring the effect of organizational commitment dimensions on employees performance: an empirical evidence from academic staff of Oyo State Owned Tertiary Institutions, Nigeria. International Journal of Academic Research in Business and Social Sciences, 4(8).

Ghozali, I \& Latan, H. (2015). Partial Least Squares: concepts, techniques and applications using the SmartPLS 3.0 program. Semarang: UNDIP Publishing Agency.

Gibson. J., Ivancevich, J., \& Donelly, J. (2012). Organizations: Behavior, structure, processes. $14^{\text {th }}$ ed. New York: The McGraw-Hill Companies, Inc.

Hira, A., \& Waqas, I. (2012). A study of job satisfaction and it's impact on the performance in the Banking Industry of Pakistan. Internatonal Journal of Business and Social Science, 3(19), 174-180.

Jogiyanto. (2011), Concepts and applications of variant-based structural equation modeling in business research, 1st ed. Yogyakarta: STIM YKPN.

Kaswan. (2012), Human resource management for organizational competitive advantage. Yogyakarta: Grha Ilmu.

Kermansaravi, F., Navidian, A., Rigi, S. N., \& Yaghoubinia, F. (2015). The relationship between quality of work life and job satisfaction of faculty members in Zahedan University of Medical Sciences. Global Journal of Health Sciences, 7(2), 228-234.

Khan, A. H., Nawaz, M. M., Aleem, M., \& Hamed, W. (2011). Impact of job satisfaction on employee performance: an empirical study of Automomous Medical Institutions of Pakistan. African Journal of Business Management, 6(7), 2697-2705.

Majumdar, M. N., Dawn, D., \& Dutta, A. (2012). Impact of quality work-life on job performance: a case study on Indian Telecom Sector. International Journal of arts and Sciences, 5(6), 655-685.

Mangkunegara, A. P. (2011), Corporate human resource management, 11th ed. Bandung: PT Remaja Rosdakarya Offset.

Memari, N., Mahdieh, O., \& Marnani, A. B. (2013). The impact of organizational commitment on employees job performance: a study of Meli Bank. Interdisciplinary Journal of Contemporary Research in Busines, 5(5), 164.

Normala, D. (2010). Investigating the relationship between quality of work life and organizational commitment amongst employees in Malaysian Firms. International Journal of Business and Management, 5(10), 7582.

Othman, A., \& Lieng., M. C. (2009). Relationship between QWL and job satisfaction: a case study of enterprose XYZ in Malacca. International Conference on Human Capital Development. ISBN 978-967-5080-517

Rafiei, M., Amini, M. T., \& Foroozandeh, N. (2014). Studying the impact of the organizational commitment on the job performance. Management Science Letters, 4, 1841-1848.

Ramadan. (2015). Quality of work life on employee performance through organizational commitment and job satisfaction as intervening variable. Journal of Development Economics, 13(02).

Rathamani, P., \& Ramchandra, R. (2013). A study on quality of work life of employees in Textile Industry - Sipcot, Perundurai. IOSR Journal of Business and Management, 8(3), 54-59. 
European Journal of Business and Management Research www.ejbmr.org

Rivai, Veithzal (2004), Human resource management for companies: from theory to practice, 1st ed. Jakarta: PT. Raja Grafindo Pesada.

Robbins, S. P. \& Judge, T. A. (2017). Organizational Behavior. 17th ed. UK: Pearson Education Limited.

Sajjad, N. K., \& Abbasi, B. (2014). Studying the relationship between quality of work life and organizational commitment. Research Journal of Recent Sciences, 3(2), 92-99.

Setiyadi, Y. W. \& Wartini, S. (2016). The effect of quality of work life on employee performance with job satisfaction as an intervening variable. Management Analysis Journal, 5 (4)

Shahbazi, B., Shokrzadeh, S., Bejani, H., Malekinia, E., \& Ghoroneh, D. (2011). A surveyof relationship between the quality of work life and performance of Department Chairpersons of Esfahan University and Esfahan Medical Science University. Procedia - Social and Behavioral Sciences, 30, 1555 - 1560.

Weiss, D., Dawis, R., England, G., \& Lofquist, L. (1967). Manual for the minnesota satisfaction questionaire. Washington DC: Research Grant RD-1613-G from the Vocational Rehabilitation Administration, Department of Health, Education, and Welfare.

Zin, R.M. (2004). Perception of professional engineers toward quality of work life and organizational commitment a case study. Gadjah Mada International Journal of Business, 6(3), 323-334. 